PontIFícIA UNIVERSIDADE CATÓLICA dO RIO DE JANEIRO

\title{
O Recursos Humanos na percepção de seus colaboradores.
}

\section{Bernardo Bacil Lourenço Ferreira}

Trabalho de Conclusão de Curso

Centro de CiênCias sociais - CCS

DePARTAMENTO dE AdMINISTRAÇÃo

Graduação em Administração de Empresas 
Bernardo Bacil Lourenço Ferreira

\section{O Recursos Humanos na percepção de seus colaboradores.}

Trabalho de Conclusão de Curso

Trabalho de Conclusão de Curso, apresentado ao programa de graduação em Administração da PUC-Rio como requisito parcial para a obtenção do titulo de graduação em Administração.

Orientador: Edmundo Eutrópio

Rio de Janeiro

Novembro de 2016. 


\section{Agradecimentos}

Agradeço a Deus minha vida, à instituição PUC-Rio pela sua excelência como instituição de ensino. A disponibilidade, contribuição e conhecimento do meu orientador, Edmundo Eutrópio, sempre atencioso.

Aos meus pais, motivadores da minha educação e que sempre contribuíram para que eu pudesse alcançar os meus objetivos. Agradeço também as amizades criadas na Puc-Rio que me ajudaram nos desafios da faculdade.

À minha amiga Letícia Monteiro, pela ajuda na revisão e conselhos. 


\section{Resumo}

Ferreira, Bernardo. O Recursos Humanos na percepção de seus colaboradores. Rio de Janeiro, 2016. 33 páginas. Trabalho de Conclusão de Curso Departamento de Administração. Pontifícia Universidade Católica do Rio de Janeiro.

Este trabalho procura mostrar algumas teorias de recursos humanos focando na teoria do autor Dave Ulrich. O trabalho faz uma análise entre as teorias de recursos humanos e a percepção dos trabalhadores da área. Ele busca analisar se a percepção sobre a área de recursos humanos está de acordo com a visão estratégica do autor Dave Ulrich utilizada pela maioria das empresas. As respostas obtidas nas entrevistas foram analisadas e com o resultado obtido foi possível traçar o perfil de recursos humanos que o respondente entendia que a área representava. Analisando os resultados da pesquisa foi possível identificar que a opinião dos profissionais da área de recursos humanos ainda não está em total acordo com o que o modelo estratégico propõe.

\section{Palavras-chave}

Recursos humanos, recrutamento e seleção, Dave Ulrich

\section{Abstract}

Ferreira, Bernardo. The perception of human resources by its employees. Rio de Janeiro, 2016. 33 p. Final Paper - Business Administration Department - Pontifícia Universidade Católica do Rio de Janeiro

This article looks to present three different theories of human resources with focus on the theory by Dave Ulrich. The article compare the perception of human resources by its employees with the theories presented. If the perception it's the same about the perception of Dave Ulrich used by most companies today. The results of the interviews made with the participants were analysed and with the answers it was possible to identify the model of human resources that the participant recognised. Looking the results obtained by the interview it was possible to observe that the opinion of the human resources employees its not in total agreement with the opinion of Dave Ulrich.

\section{Key-words}

Human Resources, Internship selection process, Dave Ulrich 


\section{Sumário}

1 O tema e o problema de estudo 1

1.1. Introdução ao tema e ao problema do estudo 1

1.2. Objetivo do estudo 2

1.3. Objetivos intermediários do estudo 2

1.4. Delimitação e foco do estudo 2

1.5. Justificativa e relevância do estudo 3

2 Revisão de literatura 4

2.1. O modelo operacional 4

2.2. O modelo de transição

2.3. O modelo Estratégico 11

3 Métodos e procedimentos de coleta e de análise de dados do estudo 18

3.1. Métodos de pesquisa utilizados 18

3.2. Procedimentos e instrumentos de coleta de dados utilizados no $\begin{array}{ll}\text { estudo } & 18\end{array}$

3.3. Formas de tratamento e análise dos dados coletados para o estudo 19

3.4. Limitações do método

4 Apresentação e análise dos resultados $\quad 21$

4.1. Resultado da Pesquisa $\quad 21$

4.1.1. Qualificação dos resultados $\quad 21$

4.1.2. Descrição e Análise dos Resultados 24

5 Conclusões e recomendações para novos estudos 30

5.1. Sugestões e recomendações para novos estudos - melhorar 32

6 Referências Bibliográficas 33

$\begin{array}{ll}\text { Anexo } 1 & 34\end{array}$ 


\section{Lista de figuras}

Figura 1: Função do RH no modelo operacional ............................................. 5

Figura 2: Visão do modelo de recursos humanos sobre o Profissional................ 6

Figura 3: Gestão de RH segundo o modelo de transição .................................. 8

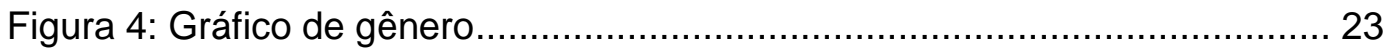

\section{Lista de Tabelas}

Tabela 1: Respostas dos participantes se trabalham ou já trabalharam na área21

Tabela 2: Tabela com as porcentagens das idades dos participantes ............... 22

Tabela 3:Tabela com a porcentagem por cargo ........................................... 22

Tabela 4:Tabela com o tempo de trabalho na área ....................................... 22

Tabela 5: Tabela com as áreas de recursos humanos que os profissionais

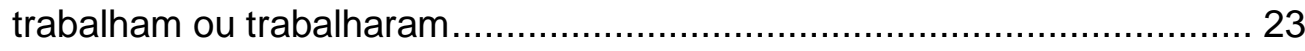

Tabela 6: Visão dos cargos sobre os modelos ……....................................... 25

Tabela 7: Total da visão dos respondentes sobre o RH estratégico .................. 26

Tabela 8: Total classificação da pesquisa por cargo ...................................... 26

Tabela 9: Avaliação de como os respondentes veem a área de recursos humanos 27

Tabela 10: Comparação das respostas sobre as perguntas 2(o $\mathrm{RH}$ participa) e 7(o $\mathrm{RH}$ participa ativamente) ........................................................... 28

Tabela 11: Comparação das respostas dos respondentes nas perguntas 6(como o $\mathrm{RH}$ ajuda a organização) e na pergunta 7(o $\mathrm{RH}$ participa no (a))............ 29 


\section{0 tema e o problema de estudo}

\subsection{Introdução ao tema e ao problema do estudo}

O cenário dos recursos humanos no mundo corporativo atual é bem complicado e a área de recursos humanos vem sendo muito questionada e muitas das vezes acaba sendo subestimada na empresa. Ao longo dos anos a sua atuação vem sofrendo mudanças nas empresas e a isso vem fazendo com que a mesma seja mais ativa. Porém, por mais que a área de recursos humanos mude a sua atuação a visão sobre a área por parte dos funcionários da empresa pode não ser a mesma visão que os profissionais querem que os outros tenham.

A atuação da área de recursos humanos vai depender das ações que serão tomadas pela área, hoje em dia o modelo que a maioria das empresas adota é o modelo estratégico, porém empresas menores não conseguem ter uma atuação de um RH estratégico e acabam tendo uma atuação mais operacional. Como o mundo corporativo é atingido pelas mudanças que ocorrem no mundo as áreas das empresas precisam sempre estar atentas as mudanças para que elas continuem a evolução.

Um grande desafio que a área de recursos humanos enfrenta nas empresas é de que sua atuação gere o valor para a empresa e que isso ajude a empresa a crescer no mercado. As ações da área precisam ajudar mesmo que indiretamente a empresa a avançar no mercado e a acompanhar os avanços que acontecem também. O autor Dave Ulrich (1997) traz uma ideia bastante diferente em relação a atuação da área de recursos humanos, ele defende justamente que as ações tomadas pela área sejam mais estratégicas e que gerem um valor maior na empresa. Por mais que as empresas usem esse modelo é importante entender o que os seus funcionários estão pensando sobre a área e o que os profissionais da área entendem sobre ela, se por exemplo a empresa aplicar o modelo de Dave Ulrich(1997), mas os seus funcionários não entenderem que a atuação da área de recursos humanos deve ser estratégica então alguma coisa está errada, pode ser na aplicação, ou na comunicação para os profissionais em como aplicar o modelo.

Analisado este cenário a pergunta que norteia o trabalho é: será que a percepção dos profissionais da área de recursos humanos está de acordo com o modelo de recursos humanos mais estratégico que Dave Ulrich propõe? 


\subsection{Objetivo do estudo}

Muitas empresas afirmam que adotam o modelo de Dave Ulrich para a área de recursos humanos, porém como as práticas adotadas no modelo possuem um foco diferente do que o tradicionalmente adotado por outros modelos, tendo em vista o seu foco muito mais estratégico, o que acaba por gerar demandas completamente diferentes para os profissionais de recursos humanos, o presente estudo tem como objetivo identificar se os profissionais de recursos humanos de empresas que declaram adotar o modelo de Dave Ulrich realmente percebem que suas empresas adotam esse modelo.

\subsection{Objetivos intermediários do estudo}

Para atingir o obejtivo final do trabalho foi importante conhecer outros modelos de recursos humanos para que assim fosse possível fazer uma comparação com o modelo do autor Dave Ulrich. Conhecer a fundo o modelo usado como referência também foi muito importante para entender os seus principais pontos e assim marcar as suas diferenças. Identificar a percepção dos funcionários de recursos humanos foi importante para poder traçar o modelo de $\mathrm{RH}$ que os partipantes idenficavam e també avaliar as práticas do $\mathrm{RH}$ estratégico caso eles identificassem o mesmo como estratégico.

\subsection{Delimitação e foco do estudo}

O estudo focou no modelo estratégico de recursos humanos proposto pelo autor Dave Ulrich(1997), no modelo de transição dos autores George Bohlander e Scott Snell(2010) e no modelo operacional do autor Antonio de Lima Ribeiro(2005). O estudo foi aplicado apenas a profissionais de recursos humanos de empresas do Rio de Janeiro no ano de 2016 e que declararam adotar o modelo do Dave Ulrich.

O presente estudo focou na identificação do alinhamento da área de recursos humanos das empresas estudadas com o modelo do Dave Ulrich, ou seja, não houve foco na avaliação dos resultados operacionais e financeiros das empresas. 


\subsection{Justificativa e relevância do estudo}

O estudo busca explicar para diversos públicos como a atuação da área de recursos humanos é percebida por quem está inserido nela. Desta forma, o trabalho é relevante para os profissionais de recursos humanos, pois ajuda a identificar se há desalinhamento entre o que é declarado e o que é realizado, auxiliando na obtenção de um melhor posicionamento da área frente às outras áreas da empresa.

Também é relevante para as empresas, pois pode ajudar a direcionar uma melhor utilização da área e dos profissionais de recursos humanos.

É relevante para a academia, uma vez que avalia a aplicação de um modelo, ajuda no desenvolvimento de posicionamento crítico para a construção de novos modelos cada vez mais adaptados ao contexto atual. 


\section{Revisão de literatura}

Esta seção foi dividida em três partes e cada uma aborda um tipo de modelo de recursos humanos. A primeira parte aborda o modelo operacional de recursos humanos do autor Antonio de Lima Ribeiro(2005), a segunda parte aborda o modelo de transição de recursos humanos dos autores George Bohlander e Scott Snell(2010) e a terceira parte aborda o modelo estratégico de recursos humanos do autor Dave Ulrich(1997).

O modelo operacional tem um foco nas suas ações partindo das funções de recursos humanos para as estratégias, o modelo de transição mescla algumas de suas ideias, em alguns pontos o modelo aborda ideias do modelo operacional, porém em outros pontos o modelo aborda ideias do modelo estratégico. O modelo estratégico foca as suas ações a partir das estratégias da organização para as funções de recursos humanos.

\subsection{0 modelo operacional}

Esta seção aborda o modelo operacional de recursos humanos proposto pelo autor Antonio de Lima Ribeiro. Ao apresentar o modelo operacional, o trabalho busca mostrar outra visão sobre o $\mathrm{RH}$ diferente da visão do modelo de transição de George Bohlander e Scott Snell e da visão estratégica de Dave Ulrich que é o foco do estudo. O modelo operacional possui diferenças para o modelo estratégico do Dave Ulrich e para o modelo de transição. Algumas dessas diferenças são destacadas no trabalho para que seja possível entender o modelo e ver a sua prática.

O modelo do autor Antonio de Lima Ribeiro é um modelo operacional no qual ele entende que a função da área de recursos humanos é atrair, reter e desenvolver o empregado da organização(FIG.1). Ribeiro (2005, p.3) Diferente da visão do modelo estratégico de Dave Ulrich que entende que a função do $\mathrm{RH}$ deve ser estratégica e ter um foco não apenas na empresa como também no cliente. A visão do autor nesse ponto ilustra bem o foco desse modelo no operacional, pois quando o autor coloca que a função da área de recursos humanos é apenas atrair o funcionário, segurá-lo e desenvolvê-lo apesar de não parecer operacional é uma prática muito operacional, pois quando é comparado ao modelo estratégico 
podemos ver que o pensamento é diferente, a empresa precisa sim ter esses principios para que se tenha sempre um bom time trabalhando para ela, porém todas as decisões tomadas pela área de recursos humanos devem ser voltadas para a empresa e para gerar resultados para ela. Quando se coloca o que o autor escreveu sobre a função de recursos humanos, é uma amostra de que o modelo é operacional. O profissional de recursos humanos precisa indicar e formular meios para avaliar a pessoa em todos os sentidos, ou seja, deve avaliar da sua formação profissional até a coleta de informações que servem para que a empresa trace o perfil do funcionário. Ribeiro $(2005$, p.1)

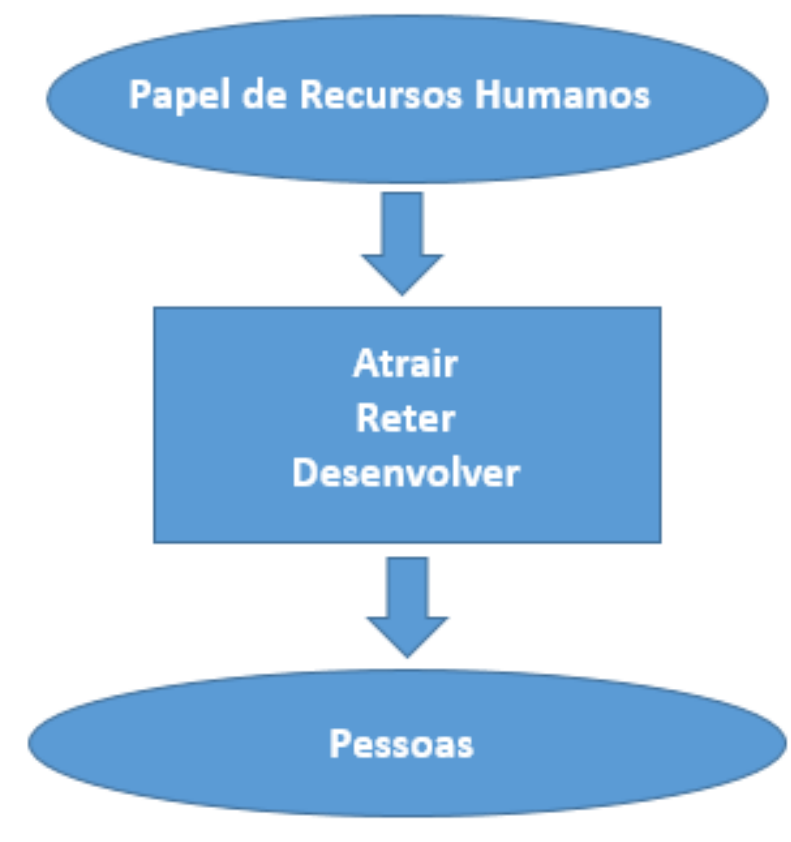

Figura 1: Função do RH no modelo operacional

\section{Fonte: Livro Gestão de recursos humanos (Ribeiro,2005)}

É importante que o profissional de recursos humanos saiba diferenciar as pessoas que ele tem contato no seu dia a dia. Cada pessoa tem uma personalidade única, com conhecimentos diferentes, hablidades diferentes e principalmente personalidades diferentes. Ribeiro $(2005$, p.3) É preciso saber que cada um tem uma reação diferente para uma mesma situação e o profissional de recursos humanos deve estar atento a esse fator. Essa identificação das diferenças entre os profissionais feita pela área de recursos humanos é uma das tarefas mais importante para a área, pois isso auxilia a empresa e a área para que possa ter os melhores resultados. Esse ponto é um ponto em comum com o modelo estratégico e com o modelo transicional. O profissional deve respeitar 
cada indivíduo como pessoa e não como recursos da organização. Por isso é muito importante que o profissional tenha uma formação mais humanista e seja dotado de uma empatia profunda para estabelecer relações proveitosas com qualquer pessoa da empresa, seja ele executivo ou trabalhador de chão de fábrica. Ribeiro (2005, p.3) A figura 2 mostra a visão do modelo operacional sobre o funcionário e a empresa, o funcionário passa a ser um negócio para empresa e o que ele tem para oferecer a ela é o talento, sem esse talento a empresa não alcança o sucesso desejado. (FIG.2)

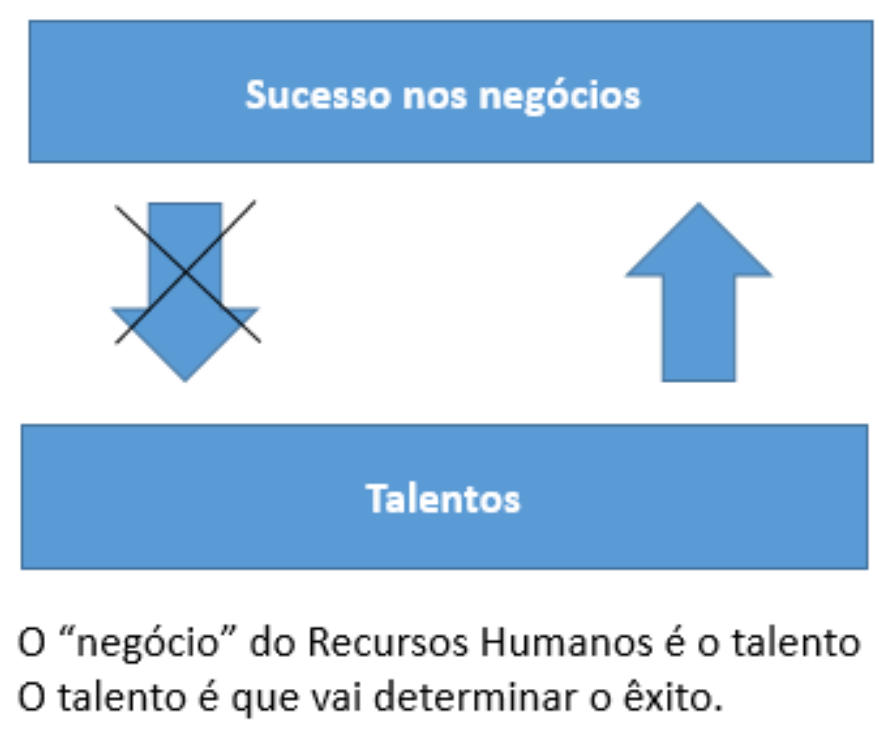

Figura 2: Visão do modelo de recursos humanos sobre o Profissional Fonte: Livro Gestão de recursos humanos (RIbeiro, 2005)

O profissional de $\mathrm{RH}$ precisa ter a noção de sua importância na organização, ele participa das ações que tem uma grande importância para a empresa e contribui para que a mesma consiga atingir os seus objetivos organizacionais. Por isso suas ações precisam e devem ser tomadas com a maior clareza e seriedade para que elas afetem a empresa de uma maneira positiva buscando sempre acrescentar a empresa e nunca a prejudicar a mesma.

A área de recursos humanos de uma empresa tem várias missões que ajudam a empresa no curto, médio e longo prazo. Essa visão está presente em todos os modelos, é necessário que se tenha uma visão desse tipo para que as ações da área de recursos humanos da empresa possam ter uma organização e possam coordenar suas ações e os resultados. Algumas missões que podemos 
destacar são: dimensionar e planejar as necessidades de pessoal no longo, médio e curto prazos, para atender às exigências do negócio e aos objetivos da empresa; atender as necessidades dos recursos humanos da organização, no longo, médio e curto prazos, além de manter todos os cargos e funções adequadamente preenchidos; prover a qualificação profissional dos recursos humanos da empresa. Ribeiro (2005, p.6)

O autor também mostra como deve se comportar o profissional em tempos de crise, ele mostra algumas ações que o profissional pode fazer para que diminua a chance de sua função ser cortada da empresa, as ações destacadas foram: manter a preocupação voltada fundamentalmente para os resultados, produtos tangíveis, custo/beneficios dos programas e não para aspectos processsualísticos; ter sempre em mente que os recursos humanos é um meio para se atingir os objetivos da empresa, e não o fim; apresentar um comportamento proativo diante dos problemas. Ribeiro $(2005$, p.8) Essas ações que o autor sugere no modelo foram importantes para que o funcionário mostrasse à empresa que no momento de crise ele estava interessado em ajudá-la, mas apesar de gostar da medida sugerida pelo autor ela ainda foca apenas no operacinal.

\subsection{O modelo de transição}

A visão dos autores George Bohlander e Scott Snell (2010) mescla ideias do modelo operacional e do modelo estratégico, por isso o modelo é classificado como modelo de transição. O modelo dos autores já mostra em alguns pontos a transição que ocorreram nas ações de recursos humanos acompanharam as mudanças que ocorrem no mundo. Os autores tratam no modelo de como as empresas precisam ter uma gestão de recursos humanos, eles exemplificam mostrando como deve ser feita uma gestão de recursos humanos eficiente para a empresa. A Figura 3 mostra como os autores entendem que os profissionais de $\mathrm{RH}$ devem fazer a gestão de recursos humanos. A figura 3 mostra que a gestão de recursos humanos precisa conectar diversas partes do gerenciamento para que assim seja possível que a gerência de recursos humanos tenha um papel crucial na empresa e que gere resultados para a mesma. 


\begin{tabular}{|c|c|c|}
\hline $\begin{array}{l}\text { Desafios } \\
\text { Competitivos } \\
\begin{array}{ll}\text { - Globalização } \\
\text { - Tecnologia } \\
\text { - Gestão de } \\
\text { mudanças } \\
\text { - Capital Humano } \\
\text { - Prontidão da } \\
\text { reação ao mercado } \\
\text { - Conteção de custos }\end{array}\end{array}$ & $\begin{array}{l}\text { Recursos Humanos } \\
\text { - Planejamento } \\
\text { - Recrutamento } \\
\text { - } \text { Seleção } \\
\text { - Projeto de trabalho } \\
\text { - } \text { Treinamento/desenvolvi } \\
\text { - } \text { mento } \\
\text { - } \text { Coliação } \\
\text { - Remunicações } \\
\text { - Beneficios } \\
\text { - Relações Trabalhistas }\end{array}$ & $\begin{array}{l}\text { Preocupações dos } \\
\text { funcionários } \\
\text { - Formação } \\
\text { - Distribuição por idade } \\
\text { - Questões relativas ao sexo } \\
\text { masculino ou feminino } \\
\text { - Segurança no trabalho } \\
\text { - Niveis de educação } \\
\text { - } \text { Direitos dos funcionários } \\
\text { - Quesões relativas à } \\
\text { - } \text { privacidade } \\
\text { Atitudes no trabalho }\end{array}$ \\
\hline
\end{tabular}

Figura 3: Gestão de RH segundo o modelo de transição

\section{Fonte: Livro Administração de recursos humanos (Bohlander e Snell,} 2010)

Para que a gestão de recursos humanos seja positiva para a empresa e gere os resultados que a organização deseja, os administradores precisam agrupar as partes do gerenciamento, partes essas que eles classificaram como desafios competitivos e preocupações de funcionários. Na parte de desafios competitivos foi possível identificar os desafios destacados no modelo estratégico de Dave Ulrich.

É destacado por exemplo, como a globalização afeta as empresas, as tecnologias onde programas começaram a mudar a atuação das áreas. Os autores destacaram que a atuação da tecnologia teve bastante impacto principalmente nas áreas que têm uma atuação mais operacional, "O impacto mais óbvio tem sido o operacional - ou seja, a automatização de tarefas de rotina, diminuindo a carga administrativa, reduzindo custos e aumentando a produtividade interna do RH propriamente dito" Bohlander e Snell (2010, p.7). No mundo atual a tecnologia precisa auxiliar a empresa e não atrapalhar, a empresa precisa saber utilizar as novas tecnologias a seu favor. O que o autor quis destacar no trecho citado mostra justamente a maneira como ocorreu a transição dos modelos, a tecnologia fez com que atividades operacionais sofressem maiores impactos e obrigou as empresas a mudar suas atividades para que elas continuassem competitivas no mercado.

É destacado também que a empresa precisa ter um gerenciamento para as mudanças, é preciso que se tenha capacidade para gerenciar todas as mudanças 
que acontecem na empresa e no mundo. As mudanças que ocorreram foram cada vez mais dinâmicas e exigiram cada vez mais da empresa uma atenção e um cuidado maior. Esse gerenciamento de mudanças pode ocorrer de diversas maneiras, os autores destacam que os dois tipos de mudança que ocorrem em uma organização são: "Mudanças reativas: Mudança que ocorre depois que forças externas já afetaram o desempenho" Bohlander e Snell (2010, p.11). O impacto causado pela globalização pode ser um exemplo de mudança reativa, se a empresa não começar a adotar a tecnologia em suas operações ela começa a ficar para trás em relação as suas concorrentes e pode começar a ter seus resultados afetados a força e a rapidez que isso vai ocorrer vai depender de como os seus concorrentes reagiram as mudanças que estão ocorrendo e as "Mudanças proativas: Mudança iniciada para tirar vantagem das oportunidades almejadas" Bohlander e Snell (2010, p.11).

Um dado interessante que foi destacado pelos autores é que "em uma pesquisa realizada pela American Management Association (AMA) é de que apesar de $84 \%$ dos entrevistados afirmarem que promovem pelo menos uma mudança em suas empresas, dois terços dos entrevistados afirmam também que a organização em que eles trabalham não possui nenhum tipo de programa formal de gerenciamento de mudanças que apoie essas iniciativas." Bohlander e Snell (2010, p.12) Esse dado apresentado no livro é interessante, pois mostra um erro cometido nas empresas e uma contradição dentro delas. O erro cometido é de não ter nenhum programa de gerenciamento de mudança na empresa(algo que no mundo de hoje é essencial para a empresa) e o contraste aparece quando um número bastante elevado dos entrevistados diz que promove mudanças na empresa mas um número bastante elevado também afirma que a empresa não tem nenhum programa de gerenciamento de mudança.

$\mathrm{O}$ que fica evidente analisando o resultado dessa pesquisa feita pela American Management Association (AMA) é que existe uma falta de comunicação da empresa com os seus funcionários, se essa comunicação existisse a empresa poderia ter uma atuação muito maior no mercado, com resultados melhores do que ela tem atualmente e os seus profissionais iriam se sentir muito mais valorizados pela mesma.

Apesar de ter algumas abordagens que são parecidas com o modelo de Dave Ulrich os autores em alguns momentos defendem práticas que ainda são muito operacionais como por exemplo o recrutamento e seleção defendido no modelo. No trecho destacado a seguir podemos ver a atuação mais operacional "Os programas de contratação devem ter como objetivo a identificação, o 
recrutamento e a contratação dos melhores e mais brilhantes talentos existentes. Os programas de treinamento complementam essas práticas de recrutamento e seleção e criam oportunidades para o aprimoramento das qualificações , principalmente em áreas que não podem ser transferidas de uma epresa para outra, caso o funcinário deixe a empresa."Bohlander e Snell (2010, p.13) Em outro momento os autores afirmam no livro "Administração de recursos humanos" (Cengage Learning, 2010) a necessidade das empresas em investir no desenvolvimento de seus funcionários. A empresa buscar o melhor profissional para a vaga faz sentido, porém que é preciso levar em conta não apenas se o profissional que está sendo escolhido pela empresa é o melhor disponível, é preciso levar em conta a personalidade desse profissional, se ela se encaixa na vaga, ela está de acordo ou dentro de um perfil que a empresa deseja, enfim existem varios pontos que a empresa precisa levar em conta em seu recrutamento e seleção que o modelo de transição não aborda da forma que o modelo estratégico aborda, ele aborda de uma forma mais operacional.

Práticas de motivação defendidas pelos autores George e Snell (2010) também mostram um pensamento mais operacional do que estratégico, em determinado momento os autores defendem a prática de remuneração por competência para o estímulo do funcionário. Apesar de ser uma prática de motivação que causa efeito no profissional, as pessoas hoje em dia precisam de uma motivação que não seja apenas momentânea(a motivação monetária acaba sendo momentânea, pois acontece poucas vezes no ano e depende muito das metas serem atingidas pelo funcionário, pela área que ele atua e pela empresa), a motivação precisa ser constante, práticas que deem uma estabilidade para 0 profissional, práticas que mostrem que a empresa está preocupada com a família do funcionário.

Ao longo do estudo foi possível identificar que o modelo descrito por Bohlander e Snell (2010) é uma transição do modelo operacional descrito pelo autor Antonio de Lima Ribeiro no livro "Gestão de pessoas" (Ribeiro, 2005) para o modelo estratégico do autor Dave Ulrich explicado no livro "Os campeões de recursos humanos" (Ulrich, 1997). Outra parte que mostra essa transição é quando os autores George Bohlander e Scott Snell citam no livro que a empresa deve estar voltada para atender as expectativas do cliente, suas ações devem visar atender os requisitos do cliente e a área de recursos humanos também está dentro desse foco, as suas ações devem estar voltadas para que os seus funcionários atendam as expectativas do cliente. Por exemplo quando uma empresa de consultoria vende um projeto para uma empresa ela precisa alocar 
seus recursos(ou contratar) de acordo com o que o projeto demanda e de acordo com o que a empresa espera que o projeto faça para ela.

Como citado anteriormente nesta seção, algumas ações do modelo ainda são bastante operacionais, os autores citam que um desafio da área de recursos humanos é conter custos, que existem empresas que querem que os seus departamentos (e principalmente o departamento de recursos humanos) cortem custos e mantenham a mesma qualidade. Essa prática ainda existe é claro, porék é uma prática mais operacional e não estratégica. Dave Ulrich defende que as práticas de recursos humanos já sejam voltadas para que elas gerem lucro para a empresa, essa estratégia evita com que se tenha esse tipo de prática como a principal fonte de redução de custos da empresa. Em determinados momentos vai ser difícil para uma empresa que ela não tenha que adotar essa prática, mesmo que ela use o modelo do Dave Ulrich, o momento que o Brasil vive atualmente, de uma crise financeira que está afetando um grande número dos setores de atuação do país acaba fazendo com que as empresas precisem tomar essas medidas, pois por mais que suas práticas sejam voltadas para o lucro com a crise isso acaba não gerando o lucro que gerava anteriormente e acaba impactando na empresa.

\subsection{O modelo Estratégico}

Nesta seção é apresentada a proposta feita pelo autor Ulrich(1997) sobre um novo modelo de recursos humanos e como a área de recursos humanos precisa se adaptar ao ambiente empresarial. As empresas se tornaram cada vez mais competitivas e isso fez com que as áreas das empresas sofressem mudanças em suas atividades. O que é citado no livro "Os campeões de recursos humanos" Ulrich (1997) é justamente que a área de recursos humanos deveria mudar a forma como atua na empresa tendo novos objetivos e como essa área sofreu mutações devido as mudanças ocorridas no mundo empresarial.

Para facilitar a compreensão em relação as mudanças que estão ocorrendo ná área de recursos humanos existem 8 desafios globais que as empresas precisam aprender a lidar para que busquem se adaptar as novas demandas do $\mathrm{RH}$, são eles:

Globalização: O modelo de transição já havia falado sobre o impacto que a globalização tem na empresa, devido ao mundo corporativo cada vez mais dinâmico as empresas já entenderam que precisam estar em constante evolução 
e precisam acompanhar a globalização para que elas estejam sempre competitivas e acompanhem sempre o mercado

Cadeia de valor para a competitividade empresarial e os serviços de $\mathrm{RH}: \mathrm{A}$ sensibilidade ao consumidor é importante para que as ações da empresa sejam voltadas para que o consumidor fique satisfeito e tenha suas necessidades atendidas pela empresa.

Lucratividade entre custo e crescimento: Os meios para que a empresa obtenha lucro sofreram mudanças, é importante que as empresas busquem ter lucro não apenas com uma atividade desenvolvida por ela, mas por meio de diversas atividades desenvolvidas, a redução de custos por exemplo é uma forma da empresa aumentar o seu lucro, ela só precisa ser feita de uma maneira que a empresa não perca a qualidade de seu produto e que o consumidor não seja prejudicado. A empresa precisa saber que a redução de custo não pode ser o único meio de aumentar o lucro, o modelo estratégico mesmo explica que as ações da área de recursos humanos devem ser voltadas para que a empresa tenha resultados positivos. Esses resultados também são resultados monetários.

O foco na capacidade: quando as promessas estratégicas se convertem em ações cotidianas, as capacidades da organização precisam ser redefinidas a fim de sustentar e integrar as competências individuais. Ulrich (1997)

Mudança de parâmetros: desafio está conectado com o primeiro desafio citado pelo Dave Ulrich o de globalização, entendo na verdade que o desafio é uma consequência da globalização e quanto mais rápido e mais naturalmente essas mudanças forem absorvidas pela organização melhor será o resultado para ela.

Tecnologia: Um desafio que já havia sido falado no modelo de transição em como a tecnologia influenciava na organização e como mudava o comportamento da mesma em determinadas ações e práticas da empresa.

Atração, retenção e mensuração da competência e do capital intelectual: com o ambiente empresarial mutável, global, e tecnologicamente exigente, a obtenção e retenção de talentos tem uma importância maior na competitividade entre as empresas. Ulrich (1997)

Reveresão não é tranformação: A empresa precisa entender que por mais que ela tenha promovido mudanças em suas práticas, que tenha alterado processos, a transformação só acontece quando ela e o cliente possuem a mesma visão.

Todos esses oito desafios são propostos pelo Dave Ulrich em seu livro "Os campeões de recursos humanos" Ulrich (1997). Como a área de recursos 
humanos precisa mudar para poder se adaptar não só a empresa, como também ao mercado ao longo dos anos novas tarefas foram criadas para os profissionais da área a fim de suprir essas novas demandas que surgiram e assim fazer com que a empresa esteja sempre adaptada ao mercado.

Dave Ulrich (1997) também defende que os profissionais de recursos humanos precisam ser ao mesmo tempo estratégicos e operacionais. Por isso precisam estar concentrados no longo e no curto prazo e suas atividades se estenderam da administração de processo à administração de pessoal.

O autor entende que a atuação da área de recursos humanos tem que ser ao mesmo tempo objetiva e estratégica, o que no mundo de hoje é o melhor caminho para a área seguir, principalmente para que ela tenha uma importância maior na empresa e assim contribuir para que a empresa seja mais integrada. Segundo Dave Ulrich(1997) os profissionais de recursos humanos precisam focar no longo e no curto prazo e as atividades precisam se estender à administração de processos que foram as ferramentas e os sistemas de recursos humanos à administração de pessoal segundo Dave Ulrich. Essas duas vertentes do recursos humanos acabaram se dividindo em quatro papéis principais de recursos humanos que são:

Administração de estratégias de recursos humanos, que é a respeito do ajuste das estratégias de $\mathrm{RH}$ à estratégia empresarial: Diagnóstico organizacional Ulrich (1997) Esse tópico é importante porque ele fala sobre uma prática em que quando é realizada da maneira correta pela área de recursos humanos a empresa se beneficia como um todo. Tendo essa prática, o profissional de recursos humanos tem um papel mais estratégico na empresa e assim a empresa consegue se adaptar à mudança mais rápido. Ao adotar essa prática o contato com o consumidor é automaticamente melhorado e assim é possível atender a demanda do mesmo com maior rapidez e também possibilita melhorar o desempenho financeiro da empresa e e consequentemente traz mais lucro para a mesma.

Administração da infraestrutura da empresa: Existem diversos exemplos de como a reengenharia de processos pode ser útil para a empresa administrar a infraestrutura, essa ação por parte da área de recursos humanos é algo que já acontece, porém com a mudança de foco para a estratégia acabou sendo minimizado. Você ter o controle sobre a infraestrutura de sua empresa e promover melhorias nela faz com que se tenha uma otimização de tempo e redução de custos, é possível mapear os processos, identificar oportunidades e erros que aconteceram ou que estão acontecendo. 
Administração da contribuição dos funcionários: Quando as empresas tem no seu capital humano uma grande importância para a execução do trabalho é preciso que o $\mathrm{RH}$ tenha um cuidado maior com seus funcionários, que ele se envolva com os problemas, que busque sempre ações para a melhoria de seus funcionários, pois quando se trabalha em uma empresa que defende os funcionários a motivação dos mesmos aumenta, o que gera um maior envolvimento dos funcionários e possibilita a empresa a crescer. A empresa mostrar para o funcionário que está se preocupando com ele faz com que o mesmo crie uma identidade com a empresa, desse jeito é possível que a sua atuação dentro da empresa seja mais forte, que seu trabalho seja o melhor que ele pode entregar e com isso o resultado da empresa pode aumentar, pois os outros funcionários também vão se sentir prestigiados pela empresa e também vão se esforçar, no final o resultado vai ser bom para todos.

Administração da transformação e da mudança: A mudança empresarial nunca é um processo que seja de fácil implementação, dependendo do tamanho da empresa e do tempo que se tem a mesma cultura isso se torna ainda mais difícil. O papel da área de recursos humanos neste tópico é justamente que ela consiga achar uma forma de implementar a mudança na empresa de uma forma rápida e eficaz. Ela deve trabalhar junto com os gestores para que seja feito o processo mais adequado e assim a mudança consiga ser gradativa e proveitosa para a empresa.

Ao longo dos anos a função de recursos humanos na empresa foi mudando, hoje temos uma função mais estratégica do $\mathrm{RH}$. Suas atividades foram voltadas para a organização e para o cliente. Além disso com a globalização e a criação dos multiplos papéis de $\mathrm{RH}$, a função do $\mathrm{RH}$ começou a ser vista de uma forma mais uniforme na empresa, suas tarefas devem estar conectadas com a cultura da empresa e com as estratégias da empresa para que se tenha um resultado melhor, para que as ações tomadas na organização estejam alinhadas com a cultura e política organizacional. Os funcionários da empresa precisam entender que todos que estão na empresa são parceiros, principalmente a área de recursos humanos. Ulrich (1997)

A função do $\mathrm{RH}$ foi mudando ao longo dos anos a medida que foi exigindo cada vez mais que a área tivesse um valor maior na empresa. Essas mudanças que ocorreram no mundo e que estão causando impacto no mundo empresarial fizeram com que o $\mathrm{RH}$ se tornasse um parceiro estratégico da empresa desempenhando diversos papéis que estivessem alinhados com as estratégias da empresa em que estavam trabalhando. Ulrich (1997) 
Para que o $\mathrm{RH}$ se tornasse um parceiro estratégico ele precisou definir a arquitetura organizacional para que ele possa entender e traduzir a estratégia que está em ação, é preciso que junto com os gerentes de linha ele tenha feito um diagnóstico organizacional eficaz, pois assim poderá verificar os gaps organizacionais e gerar novas práticas criativas e oportunas e os profissionais de $\mathrm{RH}$ precisam ser capazes de fixar prioridades paras as iniciativas e cumpri-las até o fim.

As mudanças que ocorreram na área de $\mathrm{RH}$ fizeram surgir novas maneiras mais rápidas e eficientes para realizar os trabalhos. Começou-se a surgir os especilistas administrativos. Esses especialistas surgem de acordo com 0 processo de reengenharia que a organização precisa passar ao longo dos anos, as reengenharias que aconteceram nas organizações variam em quantidade(a empresa pode precisar realizar várias reengenharias para se adequar ao mercado atual) e variam também de acordo com a necessidade que a empresa tem para melhorar seus processos.

Arthur Yeung, professor de administração de empresas na Universidade de Michigan definiiu os seguintes passos na reegenharia de $\mathrm{RH}$ (Ulrich, 1997, p.115):

1. Definir os processos-alvo

2. Desenvolver modelos 'tal como é'

3. Questionar premissas subjacentes

4. Desenvolver modelos 'como deve ser'

5. Implementar, desenvolver, vender

6. Medir impacto empresarial

O especialista administrativo não pode apenas reduzir custos e simplificar o trabalho na empresa, ele precisa pensar na criação de valor do $\mathrm{RH}$. A criação de valor se transforma ao longo dos anos devido ao foco da área de recursos humanos, a área de recursos humanos precisa estar atenta a essas mudanças para que ela continue a criar o valor que a organização deseja e que ela consiga transmitir para os seus profissionais essa criação de valor. O autor Ulrich(1997) explica que a empresa ao repensar na criação de valor do $\mathrm{RH}$ vai precisar partir de três referenciais.

O primeiro referencial vai ser evitar o impasse entre centralização e descentralização, onde o ponto principal da discussão gira em torno da relação do poder a autoridade. A dúvida fica em quem tem essa autoridade para definir os sistemas de recursos humanos, quem vai aplicar essas práticas e tomar as 
decisões referentes a realização do trabalho. É importante evitar esse impasse, pois mostra que a função do $\mathrm{RH}$ não está clara na organização, mostra que os funcionários ainda não possuem total clareza sobre a área de recursos humanos e sua atuação na organização. Por esses motivos que é necessário que os profissionais de $\mathrm{RH}$ analisem e se for o caso reestruturem seus papéis na organização.

O segundo referencial que a área de recursos humanos tem para analisar na criação de valor do $\mathrm{RH}$ é definir um referencial de criação de valor e as opções de resultado segundo Ulrich(1997) o debate sobre o poder, a influência e o controle deve ser susbtituido pelo debate sobre a criação de valor da empresa. Ulrich (1997) acredita que o valor deve ser criado pelo cliente e não por quem presta o serviço. Acho uma visão interessante sobre este referencial, pois se pensarmos que estamos sempre buscando atender o cliente não podemos ignorálo na hora da criação de valor. Isso se aplica a área de recursos humanos. No caso da área de recursos humanos o cliente na verdade é a própria empresa, porém seus processos, suas ações, suas práticas devem ser criadas de acordo com o que os clientes(funcionários da empresa) querem.

O terceiro e último referencial que Dave Ulrich destaca é o de definir um processo de criação de valor. Quando se define um processo de criação de valor a organização entende que a lógica é que o processo todo é horizontal e não vertical. A hierarquia perde espaço na questão de adicionar valor para o cliente, ou seja, todo o pensamento de que quanto maior o poder mais influência tinha na organização na verdade é o contrário. A visão do negócio como um todo muda, o valor que a organização irá adicionar ao cliente é mais importante do que a função. Existem quatro passos que segundo Dave mostram a importância do cliente e que os recursos precisam ir da organização de serviços comuns até o cliente. Os quatro passos são:

Requisitos do cliente onde a organização procura inserir o cliente nos resultados da empresa, o cliente da empresa não é apenas o cliente externo(esse é o principal cliente da empresa), dentro da organização estão os gerentes de linha e os funcionários que usam as práticas de $\mathrm{RH}$ da empresa. Eles também devem ser consultados, pois os mesmos são parceiros da organização

O segundo passo é interface com o cliente, que é segundo Ulrich (1997), quando a organização precisa selecionar o profissional de recursos humanos mais qualificado para a função já que a mesma demanda bastante conhecimento dos processos, do cliente e deve ser um profissional que a empresa confie. 
O terceiro passo é o processo que é referente aos canais que a empresa usa para alcançar seus resultados, segundo Dave a empresa pode e deve buscar diversos canais para atingir os seus resultados e não deve ficar restrita apenas aos canais que ela costuma utilizar. O terceiro passo descrito por Dave é interessante e mostra como é importante que os processos e as práticas podem e devem ser revistos ao longo dos anos, a empresa ao utilizar diversos canais para atingir aos seus resultados têm experiências diferentes e acaba descobrindo novos caminhos(melhores e mais curtos), ou seja, a empresa melhora seu desempenho utilizando diversos canais, mesmo que esse não seja o foco da empresa no momento.

O quarto passo destacado por Dave Ulrich é serviços comuns que diz respeito as fronteiras que as antigas práticas de recursos humanos criaram na empresa e a missão é justamente quebrar essas barreiras, pois a mesma criou as diferenças na organização que a criação de valor busca alterar Ulrich(1997, p.135). Quebrar essas barreiras na organização é importante para que a empresa consiga aplicar novos métodos na organização, para que ela consiga melhorar as suas práticas e principalmente para que a resistência sobre esses novos métodos seja a menor possível, pois sempre tem resistência quanto a novas práticas da empresa. 


\section{Métodos e procedimentos de coleta e de análise de dados do estudo}

\subsection{Métodos de pesquisa utilizados}

Esta pesquisa é classificada de acordo com a taxinomia de Vergara (1997), quanto aos fins é uma pesquisa exploratória, tendo em vista que visa explorar a existência e a aderência da aplicação de uma teoria nas respectivas práticas organizacionais. Quanto aos meios é uma pesquisa bibliográfica, uma vez que recorreu a literatura existente para posicionar o modelo usado como referência. $A$ presente pesquisa também se valeu de um levantamento, utilizando uma abordagem qualitativa.

\subsection{Procedimentos e instrumentos de coleta de dados utilizados no estudo}

Para a pesquisa bibliográfica a coleta de dados do trabalho foi feita de acordo com o tema proposto pelo estudo, os autores selecionados foram escolhidos por terem escrito sobre o tema do trabalho e principalmente por suas visões que foram diferentes da visão dos outros autores escolhidos no trabalho. $A$ definição desses autores foi feita pelo modelo de recursos humanos que cada um defendia, o primeiro modelo estudado foi o modelo operacional do autor Antonio de Lima Ribeiro, esse modelo apresenta uma visão mais operacional da área de recursos humanos onde o foco da área sai da função de recursos humanos para a estratégia de recursos humanos. O segundo modelo selecionado foi o modelo de transição dos autores Geoge Bohlander e Scott Snell onde os autores já possuem algumas ideias do modelo estratégico de Dave Ulrich, porém defendem também algumas ideias do modelo operacional do autor Antonio de Lima Ribeiro. E o último modelo selecionado foi o modelo estratégico do autor Dave Ulrich que tem uma visão diferente dos demais autores e modelos, onde o mesmo defende que o foco da área deve ser na estratégia da empresa.

Esses três autores e esses três tipos de modelos de recursos humanos foram selecionados para que pudessem identificar no trabalho por meio do resultado da pesquisa, o que cada participante entendia da área de recursos 
humanos e assim entender a visão dos profissionais sobre a área, atingindo o objetivo principal do estudo.

As perguntas iniciais da pesquisa do trabalho serviram para que fosse possível traçar o perfil dos respondentes, a segunda etapa da pesquisa foi retirada do livro "Os campeões de recursos humanos" Ulrich(1997, p.70), ela é composta por 10 perguntas com 4 opções cada pergunta e o entrevistado deve avaliar a qualidade da área de recursos humanos de 1(um) a 5(cinco). Sendo um para a qualidade muito baixa e cinco para a qualidade muito alta.

A coleta de dados foi feita através de um levantamento das respostas obtidas no qualtrics e nas entrevistas presenciais que foram feitas. $O$ uso da ferramenta qualtrics foi para facilitar que os respondentes tivessem o acesso a pesquisa e pudessem responder com calma e as entrevistas presenciais foram feitas simultaneamente as entrevistas online para que pudesse ser feita uma comparação com os resultados obtidos. A pesquisa obteve 42 respostas no total, sendo que 35 foram validadas. As entresvistas foram feitas com profissionais de recursos humanos, tanto com quem trabalha atualmente e com quem já trabalhou na área.

\subsection{Formas de tratamento e análise dos dados coletados para o estudo}

O trabalho possui uma abordagem qualitativa. Os dados obtidos foram analisados de forma que o trabalho pudesse traçar o perfil desses respondentes e que pudesse identificar o modelo de recursos humanos que o respondente avaliava ter atualmente. As entrevistas presenciais foram feitas com os mesmos objetivos das pesquisas disponibilizadas no Qualtrics e foram feitas também com o objetivo de identificar alguma diferença nas respostas dos participantes.

Uma vez levantados todos os dados foi feita uma confrontação do que as pessoas entrevistadas manifestaram e os diferentes posicionamentos da área de recursos humanos apresentados pelos autores utilizados como referência, tendo como objetivo identificar se a precepção indicava uma atuação mais operacional ou mais estratégica.

\subsection{Limitações do método}

Como a pesquisa foi divulgada nas redes sociais e estava disponível para quem quisesse responder, poderia acontecer de pessoas que não faziam parte do público alvo acessassem a pesquisa a fim de fazer a mesma para que ajudasse 
no trabalho. Porém essa ajuda iria fornecer uma informação falsa para o estudo e iria fazer com que a análise de resultados não fosse tão realista como o trabalho precisava que ela fosse, por isso na primeira pergunta da pesquisa a pessoa tem que responder se trabalha com a área, se já trabalhou com a área ou se nunca trabalhou. Se ela responder que nunca trabalhou a pesquisa termina, pois, a mesma não faz parte do público alvo. Outra limitação que o estudo pode ter é em relação ao modelo de pesquisa do Dave Ulrich. Quando foi feito o teste da pesquisa foi percebido, uma certa resistência com o modelo de pesquisa do Ulrich(1997), algumas pessoas não entenderam as perguntas, outras acharam que as perguntas eram muito incisivas em relação ao recursos humanos. Para amenizar esse problema foi introduzido um texto explicativo do modelo para que os respondentes pudessem ter uma visão melhor sobre as perguntas e também para que não tivesse nenhuma influência negativa no resultado da pesquisa.

A entrevista possui algumas limitações, ela não poderia ser muito extensa para que o entrevistado não parasse de responder a pesquisa no meio, para a pesquisa exploratória precisa dispor do tempo do entrevistado. A pesquisa bibliográfica tem suas limitações quanto aos métodos consultados, pois a análise fica restrita apenas aos métodos estudados e apresentados no trabalho. Os dados aprensentados na pesquisa bibliográfica podem estar errados é importante que o pesquisador busque informações sobre os dados e as fontes para que os dados apresentados no estudo sejam verídicos. 


\section{Apresentação e análise dos resultados}

\subsection{Resultado da Pesquisa}

\subsubsection{Qualificação dos resultados}

Os respondentes da pesquisa foram profissionais de recursos humanos, tanto os profissionais que trabalham atualmente quanto os profissionais que já trabalharam na área de recursos humanos. A pesquisa teve um total de 35 respostas, onde 32 respostas foram obtidas por meio eletrônico (a pesquisa foi disponibilizada no Qualtrics e distribuída pelas redes sociais e e-mail) e 3 respostas em entrevistas individuais feitas presencialmente com profissionais de recursos humanos. Das 32 respostas obtidas no qualtrics, 21 foram de pessoas que trabalham atualmente na área e 12 foram de respondentes que não estão trabalhando no momento, porém já trabalharam na área. $O$ filtro da pesquisa foi em pessoas que trabalham atualmente e que já trabalharam na área. Os respondentes que afirmaram que não trabalham na área foram descartados da pesquisa.

\begin{tabular}{lll} 
Resposta & $\%$ & Contar \\
\hline $\begin{array}{l}\text { Sim, trabalho } \\
\text { atualmente }\end{array}$ & $52.50 \%$ & 21 \\
\hline Não, mas já trabalhei & $30.00 \%$ & 12 \\
\hline Não, nunca trabalhei & $17.50 \%$ & 7 \\
\hline
\end{tabular}

Tabela 1: Respostas dos participantes se trabalham ou já trabalharam na área

A idade mínima dos respondentes foi 18 anos e idade máxima de 40 anos. Os respondentes de 24 a 29 anos corresponderam a maioria das respostas, no total da pesquisa eles corresponderam a $43,75 \%$, seguido dos respondentes de 18 a 23 anos que correspondem a $31,25 \%$ do total obtido. 


\begin{tabular}{ll}
\hline Resposta & $\%$ \\
\hline 18 a 23 anos & $31.25 \%$ \\
\hline 24 a 29 anos & $43.75 \%$ \\
\hline 30 a 34 anos & $12.50 \%$ \\
\hline 36 a 40 anos & $9.38 \%$ \\
\hline 40 anos ou mais & $3.13 \%$ \\
\hline Total & $100 \%$ \\
\hline
\end{tabular}

Tabela 2: Tabela com as porcentagens das idades dos participantes

Em relação aos cargos que os respondentes ocupam, os cargos de estagiário e analista corresponderam a $68,76 \%$ do total obtido. Sendo a maioria dos respondentes estagiários que correspondem a 40,63\% das respostas.

\begin{tabular}{ll} 
Resposta & $\%$ \\
\hline Estagiário & $40.63 \%$ \\
\hline Analista & $28.13 \%$ \\
\hline Consultor & $15.63 \%$ \\
\hline Gerente & $9.38 \%$ \\
\hline Diretor & $3.13 \%$ \\
\hline Outros & $3.13 \%$ \\
\hline Total & $100 \%$ \\
\hline
\end{tabular}

\section{Tabela 3:Tabela com a porcentagem por cargo}

Apesar da maioria dos respondentes ser de estagiários, quando os respondentes foram perguntados sobre o tempo na área, a maioria afirmou que trabalha ou que trabalhou mais de 2 anos, correspondendo a $40,63 \%$ da pesquisa.

\begin{tabular}{ll} 
Resposta & $\%$ \\
\hline 6 meses & $28.13 \%$ \\
\hline 1 ano & $9.38 \%$ \\
\hline 1 ano e meio & $15.63 \%$ \\
\hline 2 anos & $6.25 \%$ \\
\hline Mais de 2 anos & $40.63 \%$ \\
\hline Total & $100 \%$ \\
\hline
\end{tabular}

Tabela 4:Tabela com o tempo de trabalho na área 
As áreas de recrutamento e seleção, treinamento e departamento pessoal correspondem a maioria dos respondentes da pesquisa. Esses cargos juntos correspondem a $75 \%$ da amostra.

\begin{tabular}{ll} 
Resposta & $\%$ \\
$\begin{array}{l}\text { Recrutamento e } \\
\text { seleção }\end{array}$ & $40.63 \%$ \\
\hline Treinamento & $18.75 \%$ \\
\hline Departamento pessoal & $15.63 \%$ \\
\hline Segurança do trabalho & $0.00 \%$ \\
\hline Outros & $25.00 \%$ \\
\hline Total & $100 \%$ \\
\hline
\end{tabular}

Tabela 5: Tabela com as áreas de recursos humanos que os profissionais trabalham ou trabalharam

No total da pesquisa a divisão entre homens e mulheres nos respondentes foi de $56 \%$ de respondentes do sexo feminino e $44 \%$ do sexo masculino, porém isso não influenciou na pesquisa.

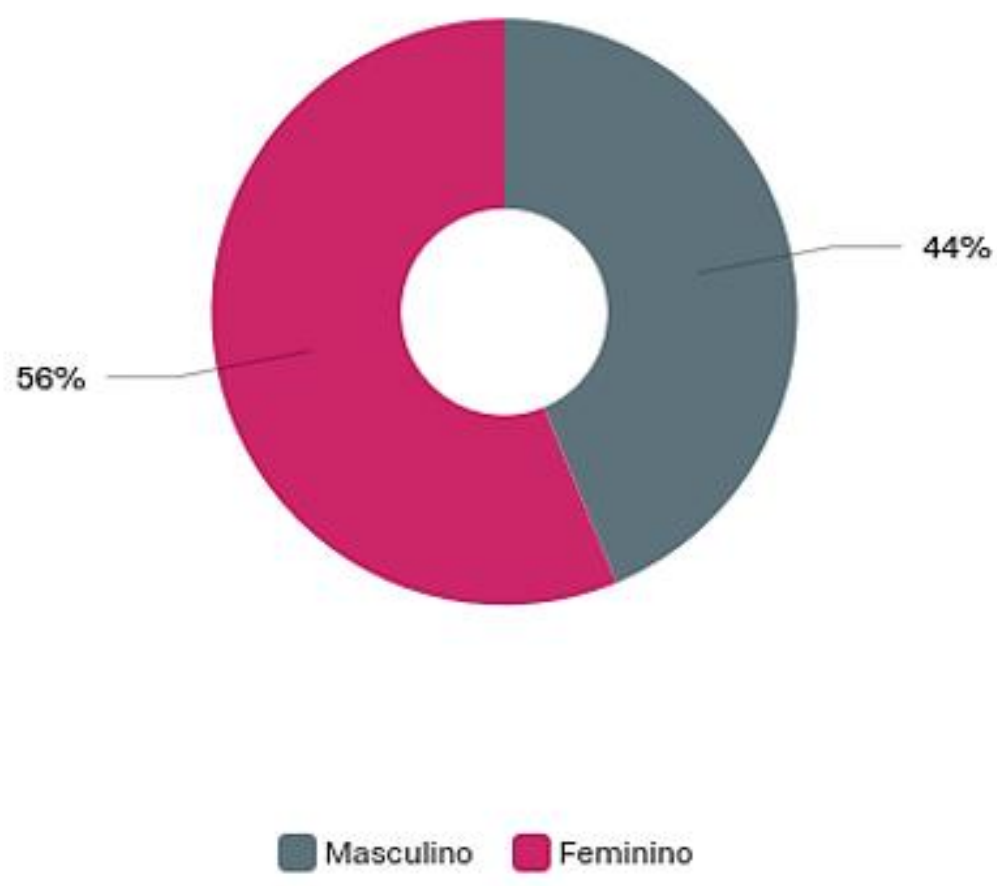

Figura 4: Gráfico de gênero 


\subsubsection{Descrição e Análise dos Resultados}

A primeira parte da pesquisa possibilitou o autor a traçar o perfil dos respondentes, o perfil traçado foi de jovens onde a maioria tem idade de 24 a 29 anos, sendo que $52 \%$ dos respondentes trabalha com a área de recursos humanos, o sexo feminino representa $56 \%$ da pesquisa enquanto o o sexo masculino corresponde a $44 \%$. Os cargos que mais estiveram presentes na pesquisa foram os cargos de estagiário e analista.

A segunda etapa foi possível identificar o nível que os respondentes avaliavam a área de recursos humanos e também foi possível identificar o que eles achavam da atuação da área de recursos humanos. Analisando as respostas foi possível ver a visão dos respondentes sobre a área de recursos humanos ser mais estratégica ou mais operacional.

Realizando os dois tipos de entrevistas foi percebido que os respondentes quando entrevistados pela internet parecem ficar mais comedidos, não se empolgam muito em dar opiniões, enquanto os participantes quando são entrevistados e gravados(com autorização dos mesmos) eles ficam mais a vontade para dar as suas opiniões, mesmo que seja na parte de classificar as afirmações como foi feito no segundo bloco da pesquisa, quando a entrevista é individual e presencial a participação dos participantes é maior do que quando os participantes que responderam por meio eletrônico.

As perguntas do modelo de pesquisa de Dave Ulrich utilizadas na segunda parte da pesquisa como forma de avaliação de recursos humanos, tinham algumas opções de respostas iguais para perguntas diferentes, porém elas não atrapalharam na avaliação e na classificação da visão dos respondentes,pois eram importantes para a avaliação da pesquisa como um todo e o foco das perguntas era diferente. Por mais que tivesse uma opção igual o objetivo da pergunta era diferente, por exemplo, na pergunta número 11 da pesquisa foi perguntado ao participante como ele vê o $\mathrm{RH}$ dedicando o seu tempo e uma das respostas para que o participante avaliasse era ouvir e responder os funcionários. $\mathrm{Na}$ pergunta seguinte pede-se para que o respondente avalie se o $\mathrm{RH}$ participa ativamente e a opção de ouvir e responder os funcionários aparece novamente para que seja avaliada. Essas duplicidades foram instrumentos utilizados pelo autor para avaliar a opinião do respondente na questão da veracidade do mesmo, ou seja, nas perguntas citadas se o participante avalia que a área de recursos humanos dedica o seu tempo a ouvir e responder o funcionário (dar a nota máxima

5 para esse item) e logo depois na pergunta seguinte ele avalia como 2 a 
participação ativa do $\mathrm{RH}$ em ouvir e responder o funcionário, identifica-se nas respostas uma contradição do respondente.

Analisando as respostas obtidas do modelo do Dave Ulrich 65\% dos respondentes avaliaram a qualidade da área de recursos humanos como muito alta (muito alta é o maior grau do método e muito baixa é o menor grau).

\begin{tabular}{|l|r|r|r|}
\hline $\begin{array}{c}\text { Cargo/resultado } \\
\text { do modelo }\end{array}$ & Operacional & Transicional & Estratégico \\
\hline Analista & $0 \%$ & $0 \%$ & $23 \%$ \\
Consultor & $\mathbf{8} \%$ & $\mathbf{8} \%$ & $4 \%$ \\
Diretor & $0 \%$ & $0 \%$ & $8 \%$ \\
Estagiário & $\mathbf{4} \%$ & $0 \%$ & $19 \%$ \\
Gerente & $0 \%$ & $0 \%$ & $12 \%$ \\
Total & $\mathbf{1 2 \%}$ & $\mathbf{2 3} \%$ & $\mathbf{6 5 \%}$ \\
\hline
\end{tabular}

\section{Tabela 6: Visão dos cargos sobre os modelos}

Na pontuação final de cada respondente foi possível avaliar a opinião do mesmo, se ele tiver tido uma pontuação final superior a 160 pontos quer dizer que ele avalia a qualidade da área de recursos humanos como muito alta e que a atuação da mesma está sendo estratégica, se a avaliação tiver uma pontuação final menor que 90, significa que o respondente avalia a área de recursos humanos como muito baixa e que a atuação da área é mais operacional como pode ser visto nas tabelas 6 e 7. Ninguém avaliou a qualidade do $\mathrm{RH}$ como muito baixa na pesquisa, apesar de ter tido um resultado em que se chegou muito perto da avaliação da área ser classificada como muito baixa (a pontuação do respondente foi de 91). Dos participantes que avaliaram a qualidade como baixa, eles representam $8 \%$ da pesquisa e ocupam o cargo de consultor na empresa que trabalham. Apenas um respondente avaliou a qualidade como nem baixa nem alta representando $4 \%$ da amostra total e ocupa o cargo de analista, eles juntam representam $12 \%$ da pesquisa que identificaram o modelo de recursos humanos como operacional. $23 \%$ dos respondentes avaliaram a qualidade como alta e identificara o modelo de $\mathrm{RH}$ sendo o modelo de transição. Concluiu-se com o resultado da pesquisa que a visão de um $\mathrm{RH}$ estratégico atinge mais da metade dos profissionais que estão inseridos no mercado e dos profissionais que já atuaram na área. Porém foi possível identificar que 35\% dos participantes não 
entendem a atuação do $\mathrm{RH}$ como estratégica, conforme o autor Dave Ulrich propõe que seja.

\begin{tabular}{|l|r|}
\hline $\begin{array}{l}\text { Visão do rh } \\
\text { estratégico }\end{array}$ & Total \\
\hline Sim & $65 \%$ \\
Não & $35 \%$ \\
\hline
\end{tabular}

Tabela 7: Total da visão dos respondentes sobre o RH estratégico

Dos cargos analisados na pesquisa, as percepções dos mesmos sobre a área foram bastante interessantes, confome tabela 8 todos os analistas que responderam a pesquisa classificaram a qualidade da área como muito alta. Os consultores tiveram um resultado mais equilibrado onde $20 \%$ classificou a área como muito alta e $40 \%$ classifou como uma qualidade baixa, os outros $40 \%$ classificaram a qualidade alta. Os estagiários tiveram um resultado mais equilibrado também em relação a avaliação da qualidade da área de recursos humanos, $43 \%$ classificam a qualidade como muito alta, 37\% como alta e apenas $20 \%$ como baixa. Para os diretores que responderam a pesquisa a qualidade da área é muito alta, assim como os gerentes que responderam a pesquisa também classificaram a qualidade como muito alta.

\begin{tabular}{|l|r|r|r|r|r|}
\multicolumn{1}{|c|}{ Cargos } & $\begin{array}{c}\text { Muito } \\
\text { baixa }\end{array}$ & Baixa & $\begin{array}{c}\text { Nem } \\
\text { baixa } \\
\text { nem } \\
\text { alta }\end{array}$ & \multicolumn{1}{|c|}{ Alta } & \multicolumn{1}{c|}{$\begin{array}{c}\text { Muito } \\
\text { alta }\end{array}$} \\
\hline Estagiário & $0 \%$ & $\mathbf{2 0 \%}$ & $0 \%$ & $\mathbf{3 7 \%}$ & $\mathbf{4 3 \%}$ \\
Analista & $0 \%$ & $0 \%$ & $0 \%$ & $0 \%$ & $\mathbf{1 0 0 \%}$ \\
Consultor & $0 \%$ & $\mathbf{4 0 \%}$ & $0 \%$ & $\mathbf{4 0 \%}$ & $\mathbf{2 0 \%}$ \\
Gerente & $0 \%$ & $0 \%$ & $0 \%$ & $0 \%$ & $\mathbf{1 0 0 \%}$ \\
Diretor & $0 \%$ & $0 \%$ & $0 \%$ & $0 \%$ & $\mathbf{1 0 0 \%}$ \\
\hline
\end{tabular}

Tabela 8: Total classificação da pesquisa por cargo

Uma das peguntas pedia para o respondente avaliar como ele via a área de recursos humanos, as opções foram parceiro estratégico, especialista administrativo, defensor dos funcionários e agente da mudança. $O$ autor Dave Ulrich destaca em seu livro que para que o $\mathrm{RH}$ atue de uma maneira estratégica é preciso que ele tenha essas quatro opções ativas na sua atuação. Analisando as respostas na tabela 9 dos participantes com visão estratégica da área foi 
possível identificar nesta pergunta que as avaliações não foram uniformes, ou seja, houve diferenças nas respostas dos respondentes, mostrando que a atuação da área de recursos humanos não está sendo aplicada da forma como o modelo pede que seja.

Para que a qualidade da área de recursos humanos fosse considerada muito alta e o $\mathrm{RH}$ fosse considerado estratégico o participante deveria obter uma pontuação total acima de 160 pontos. Essa pontuação total é o somatório de todas as respostas dadas pelo participante na pesquisa.

O que mostra que o modelo não está sendo aplicado da maneira que o autor propõe é justamente a diferença de avaliação nas opções dos resultados estratégicos. Apesar do resultado da pesquisa ter dado estratégico a atuação desses quatro pilares do modelo não está sendo feita da maneira correta, tanto é que as avaliações não estão sendo uniformes da maneira que o autor pede. Das avaliações estratégicas $46 \%$ tiveram avaliações diferentes do que o autor espera.

\begin{tabular}{|r|r|r|r|r|r|}
$\begin{array}{c}\text { Pontuação } \\
\text { geral do } \\
\text { respondente }\end{array}$ & $\begin{array}{c}\text { Opção 1: } \\
\text { Parceiro } \\
\text { estratégico }\end{array}$ & $\begin{array}{c}\text { Opção 2: } \\
\text { Especialista } \\
\text { administrativo }\end{array}$ & $\begin{array}{c}\text { Opção 3: } \\
\text { Defensor dos } \\
\text { funcionários }\end{array}$ & $\begin{array}{c}\text { Opção } \\
4: \\
\text { Agente } \\
\text { da }\end{array}$ & $\begin{array}{c}\text { Total das } \\
\text { respostas } \\
\text { mudança }\end{array}$ \\
\hline 174 & 4 & 4 & 5 & 4 & 17 \\
170 & 3 & 3 & 4 & 3 & 13 \\
163 & 4 & 3 & 2 & 5 & 14 \\
186 & 5 & 5 & 5 & 5 & 20 \\
164 & 5 & 3 & 3 & 4 & 15 \\
163 & 3 & 4 & 5 & 4 & 16 \\
177 & 5 & 4 & 4 & 5 & 18 \\
173 & 5 & 4 & 3 & 5 & 17 \\
181 & 5 & 2 & 1 & 5 & 13 \\
161 & 5 & 3 & 3 & 4 & 15 \\
165 & 4 & 4 & 3 & 4 & 15 \\
174 & 4 & 3 & 3 & 4 & 14 \\
165 & 5 & 1 & 3 & 4 & 13 \\
173 & 4 & 5 & 5 & 4 & 18 \\
161 & 5 & 4 & 4 & 4 & 18 \\
168 & 4 & 5 & 5 & 16 \\
\hline
\end{tabular}

Tabela 9: Avaliação de como os respondentes veem a área de recursos humanos 
Outro ponto importante identificado na análise das respostas da pesquisa dos respondentes com visão estratégica, foi de que quando o respondente avaliava a participação do $\mathrm{RH}$ na empresa ele tinha duas perguntas sobre o tema. A primeira pergunta sobre a avaliação da participação pedia para ele avaliar a participação como um todo, a segunda pedia para o respondente avaliar a participação ativa da área de recursos humanos, duas opções de respostas eram parecidas nessas perguntas e foi possível identificar algumas diferenças. As opções eram sobre a participação do $\mathrm{RH}$ na modelagem de mudança de cultura para renovação e transformação. Alguns respondentes entenderam que o $\mathrm{RH}$ tem a participação nessa parte e tem uma participação ativa também, porém 15\% entenderam que o RH tem uma participação, mas não é ativa.

\begin{tabular}{|c|r|r|}
$\begin{array}{c}\text { Pontuação } \\
\text { geral do } \\
\text { respondente }\end{array}$ & $\begin{array}{c}\text { Opção } 8 \\
\text { pergunta } 6\end{array}$ & \multicolumn{2}{|c}{$\begin{array}{c}\text { Opção 28 } \\
\text { pergunta 12 }\end{array}$} \\
\hline 174 & & 5 \\
170 & 5 & 5 \\
163 & 5 & 4 \\
186 & 5 & 5 \\
164 & 5 & 4 \\
163 & 5 & 4 \\
177 & 5 & 4 \\
173 & 5 & 5 \\
181 & 5 & 5 \\
161 & 5 & 4 \\
165 & 4 & 4 \\
174 & 5 & 5 \\
165 & 5 & 5 \\
173 & 5 & 3 \\
161 & 5 & 3 \\
168 & 4 & 5 \\
\hline
\end{tabular}

Tabela 10: Comparação das respostas sobre as perguntas 2(o RH participa) e 7(o RH participa ativamente)

Nas duas primeiras perguntas foi pedido para que os respondentes avaliassem como o o $\mathrm{RH}$ ajuda a organização (pergunta 6) e como o RH participa na organização (pergunta 7). Comparando os resultados dos respondentes que tiveram a pontuação maior que 160 , a maioria das respostas foi coerente na 
avaliação, apenas duas respostas que tiveram uma diferença maior na percepção sobre como o $\mathrm{RH}$ ajuda a organização e como o $\mathrm{RH}$ participa. Essa diferença pode mesmo ter acontecido dependendo de como o $\mathrm{RH}$ atua ou atuou na empresa que os respondentes trabalham ou trabalharam.

\begin{tabular}{|r|r|r|}
\hline $\begin{array}{c}\text { Pontuação } \\
\text { geral do } \\
\text { respondente }\end{array}$ & $\begin{array}{c}\text { Opção } 4 \\
\text { pergunta } 6\end{array}$ & $\begin{array}{c}\text { Opção 8 } \\
\text { pergunta } 7\end{array}$ \\
\hline 174 & 4 & 5 \\
170 & 5 & 5 \\
163 & 5 & 5 \\
186 & 3 & 5 \\
164 & 4 & 5 \\
163 & 5 & 5 \\
177 & 5 & 5 \\
173 & 5 & 5 \\
181 & 5 & 5 \\
161 & 5 & 5 \\
165 & 4 & 5 \\
174 & 4 & 5 \\
165 & 5 & 5 \\
173 & 4 & 5 \\
161 & 4 & 5 \\
168 & 3 & 4 \\
\hline
\end{tabular}

Tabela 11: Comparação das respostas dos respondentes nas perguntas 6(como o $\mathrm{RH}$ ajuda a organização) e na pergunta 7(o $\mathrm{RH}$ participa no (a)) 


\section{Conclusões e recomendações para novos estudos}

Este trabalho teve como objetivo analisar a percepção dos profissionais de recursos humanos sobre a área de recursos humanos. Como a área de recursos humanos vem sofrendo mudança ao longo dos anos e sua atuação também precisou ser modificada, o trabalho buscou analisar por meio de pesquisa essa percepção dos profisisonais. Os profissionais que o trabalho avaliou foram os profissionais de recursos humanos que atuam e os que já atuaram na área anteriormente. Avaliar a percepção dos profissionais em relação a área que eles atuam se mostrou importante, pois foi possível identificar se as práticas e os métodos utilizados pelas empresas conseguem transmitir para o profissional o seu propoósito e se suas ações estão adequadas com o que se exige dos profissionais de recursos humanos atualmente.

Para que o trabalho tivesse uma análise mais encorpada foram estudados três autores que falam sobre a área de recursos humanos. O primeiro a ser estudado foi o autor Antonio de Lima Ribeiro (2005) onde ele apresenta uma visão mais operacional da área de recursos humanos, depois foi estudado o modelo de transição dos autores George Bohlander e Scott Snell (2010) onde eles apresentaram uma visão de transição de um modelo de recursos humanos operacional para um modelo mais estratégico. Em alguns pontos eles questionam os mesmos pontos que o modelo estratégico de Dave Ulrich questiona e em outros pontos abordam práticas que estão de acordo com o modelo operacional do autor Antonio de Lima Ribeiro. Para finalizar a parte teórica foi estudado o modelo estratégico do autor Dave Ulrich (1997), esse modelo foi usado como o modelo principal do trabalho por tratar diversas práticas de recursos humanos de uma maneira mais estratégica que os demais modelos.

Para atingir os objetivos pretendidos realizou-se uma pesquisa qualitativa e bibliográfica. A pesquisa qualitativa serviu para que o trabalho pudesse comparar as respostas com os dados obtidos na revisão de literatura. Foram realizadas 35 entrevistas com profissionais de recursos humanos sendo 32 obtidas no qualtric e 
3 entrevistas presenciais e os dados das entrevistas foram tratados através da plataforma qualtrics e assim foi possível realizar a análise dos mesmos.

Analisando os resultados da pesquisa, foi possível identificar que os profissionais de recursos humanos costumam ficar bastante tempo na área já que $40 \%$ dos respondentes trabalham ou trabalharam mais de dois anos em recursos humanos. Além disso 65\% da amostra identifica a qualidade da área de recursos humanos como muito boa e identifica a atuação do RH como estratégica. Porém ainda é possível ver um grande número, 35\%, de profissionais que não identifcam a área como estratégica.

Dentro desses 35\% é importante destacar que nenhum dos repondentes avaliou a qualidade da área de recursos humanos como muito baixa, porém considero que por mais que a área tenha tido uma avaliação muito alta de mais da metade da pesquisa, ter ainda $35 \%$ de avaliação entre boa e baixa é uma questão a ser levada em conta. As práticas de recursos humanos podem não estar tendo o efeito que é esperado que elas tenha ou o departamento de recursos humanos não está conseguindo passar para os profissionais que estão no mercado o verdadeiro sentido de suas práticas.

Ao analisar os resultados da pesquisa podemos constatar também que quando o respondente tem um cargo maior na empresa(gerente, diretor) as opiniões sobre a área e as visões sobre a mesma são parecidas e atingem o mesmo resultado. $\mathrm{Na}$ análise de resultados tantos os gerentes quantos os diretores tiveram $100 \%$ de avaliações da qualidade da área de recursos humanos como muito alta. Porém ao contrário dos cargos de gerente e diretor os cargos de estagiário e consultor tiveram um resultado mais distribuido entre as opções, sendo o cargo de consultor o único a não ter a avaliação da qualidade da área muito alta como a predominante no resultado. O cargo de analista se juntou aos cargos de gerente e diretor e todas as avaliações feitas deram o resultado da qualidade como muito alta.

Ao analisar as respostas dos participantes que tiveram uma pontuação no modelo de pesquisa do autor Dave Ulrich superior a 160(pontuação que correspondia a avaliação da qualidade área de recursos humanos como muito alta e que mostrava que o respondente via a área como estratégica) foi possível identificar que algumas práticas que o autor do modelo estratégico propões não estavam sendo percebidas com unânimidade por esses respondentes. Por 
exemplo quando os respondentes foram perguntados sobre como eles viam o $\mathrm{RH}$ as opções das perguntas deveriam ter um resultado uniforme ou pelo menos parecido, pois para Ulrich o $\mathrm{RH}$ estratégico é a junção das quatro opções de avaliação da pergunta (parceiro estratégico, especialista administrativo, defensor dos funcionários e agente de mudança) e quando se tem na resposta de como o participante ve o $\mathrm{RH}$ uma diferença alta entre as opções fica claro que apesar do respondente entender a atuação da área de recursos humanos como estratégica ele não está tendo a visão clara sobre o papel da área que o autor propõe.

O objetivo do trabalho foi alcançado, ao final da análise foi possível identificar a percepção dos profissionais e foi possível identificar que 35\% dos profissionais estudados ainda não entendem que a atuação da área de recursos humanos é estratégica.

\subsection{Sugestões e recomendações para novos estudos - melhorar}

O estudo feito no presente trabalho pode ser aprofundado, aplicando o questionário para profissionais de outras áreas. Assim seria interessante após a aplicação comparar os dados obtidos com a pesquisa dos profissionais de outras áreas e com os dados obtidos com a pesquisa com os profissionais de recursos humanos e assim é formada uma avaliação total do $\mathrm{RH}$. 


\section{Referências Bibliográficas}

Bohlander e Snell, G. S. Administração de recursos humanos. São Paulo: Cengage Learning, 2010

DINIZ, DANIELA. O PASSO A PASSO DO RH EM 15 ANOS NO BRASIL. Revista Você $\mathrm{RH}$, São Paulo, 27 jun. 2016. Disponível em: <http://exame.abril.com.br/revista-voce-rh/edicoes/16/noticias/a-evolucao-do-rh>. Acesso em: 27 de junho de 2016.

ULRICH, DAVE. Os Campeões de recursos humanos. São Paulo: Futura, 1997

Ulrich, Dave: A new mandate for human resources. Harvard, Boston, v. 1, n. 1, jan. /feb. 1998. Disponível em: < https://hbr.org/1998/01/a-new-mandate-for-humanresources >. Acesso em: 20 set. 2016.

Ribeiro, ANTÔNIO Gestão de pessoas. São Paulo: Saraiva, 2005.

VERGARA, Sylvia. Projetos e relatórios de pesquisa em administração.9 ed. São Paulo: Atlas, 2007. 


\section{Anexo 1}

Entrevista no Qualtrics

Olá, Gostaria de contar com sua colaboração nessa pesquisa para o meu trabalho de conclusão de curso de Administração na PUC RIO. O objetivo dela é entender um pouco mais a percepção dos profissionais de recursos humanos sobre à área. $\quad$ Por favor, responda se você atua ou já atuou nesta área. A pesquisa não tomará muito do seu tempo e não é necessário se identificar. Sua opinião sincera contribuirá para o sucesso da minha pesquisa. Desde já agradeço a sua participação.

Q19 Você trabalha em $\mathrm{RH}$ ?

O Sim, trabalho atualmente (1)

O Não, mas já trabalhei (2)

O Não, nunca trabalhei (3)

Se sim, trabalho atualmente é Selecionado, Então ir para Gênero. Se não, mas já trabalhei é Selecionado, Então ir para Gênero. Se não, nunca trabalhei é Selecionado, então ir para Fim da pesquisa

\footnotetext{
Q1 Gênero

O Masculino (1)

O Feminino (2)

Q2 Idade

O 18 a 23 anos (1)

O 24 a 29 (2)

O 30 a 34 (3)

O 35 a 39 (4)

O 40 anos ou mais (5)
} 


\section{Q3 Cargo que ocupa}

O Estagiário (1)

O Analista (2)

O Consultor (3)

O Gerente (4)

Diretor (5)

O Outros (6)

\section{Q4 Tempo na área}

O 6 meses (1)

O 1 ano (2)

O 1 ano e meio (3)

O 2 anos (4)

O Mais de 2 anos (5)

Q18 Qual área do $\mathrm{RH}$ você atua ou atuou?

O Recrutamento e seleção (1)

O Treinamento (2)

O Departamento pessoal (3)

O Segurança do trabalho (4)

Outros (5)

A pesquisa a seguir explora diferentes papéis que a função de $\mathrm{RH}$ pode desempenhar dentro de sua empresa. Pontue por favor, a qualidade corrente de cada uma das seguintes atividades de recursos humanos, utilizando uma escala de cinco pontos (1 para baixa; 5 para alta)

Q6 O RH ajuda a oganização a...

\begin{tabular}{|c|c|c|c|c|c|}
\hline & $1(1)$ & $2(2)$ & $3(3)$ & $4(4)$ & $5(5)$ \\
\hline $\begin{array}{l}\text { Alcançar as metas empresariais (1) } \\
\text { melhorar a eficiência operacional }\end{array}$ & 0 & 0 & 0 & 0 & 0 \\
(2) $\quad \begin{array}{l}\text { Cuidar das necessidades pessoais } \\
\text { dos funcionários (3) } \\
\text { Adaptar-se a mudança (4) }\end{array}$ & 0 & 0 & 0 & 0 & 0 \\
\hline
\end{tabular}


Q7 O RH participa no(a)...

\begin{tabular}{|c|c|c|c|c|c|}
\hline $\begin{array}{c}\text { Processo de definição das } \\
\text { estratégias empresariais (1) } \\
\begin{array}{c}\text { No desenvolvimento dos processos } \\
\text { de } \mathrm{RH}(2)\end{array}\end{array}$ & 0 & 0 & 0 & 0 & 0 \\
$\begin{array}{c}\text { Aumento da dedicação dos } \\
\text { funcionários (3) } \\
\begin{array}{c}\text { Modelagem de mudança de cultura } \\
\text { para renovação e transformação (4) }\end{array}\end{array}$ & 0 & 0 & 0 & 0 & 0 \\
\hline
\end{tabular}

Q8 O RH garante que...

\begin{tabular}{|c|c|c|c|c|c|}
\hline & $1(1)$ & $2(2)$ & $3(3)$ & $4(4)$ & $5(5)$ \\
\hline $\begin{array}{l}\text { As estratégias de } \mathrm{RH} \text { estejam } \\
\text { ajustadas à estratégia empresarial (1) }\end{array}$ & 0 & 0 & 0 & 0 & 0 \\
\hline $\begin{array}{l}\text { Os processos de } \mathrm{RH} \text { sejam } \\
\text { administrados com eficiência }(2)\end{array}$ & 0 & 0 & 0 & 0 & 0 \\
\hline $\begin{array}{l}\text { As políticas e programas de } \mathrm{RH} \\
\text { respondam às necessidades pessoais dos } \\
\text { funcionários (3) }\end{array}$ & 0 & 0 & 0 & 0 & 0 \\
\hline $\begin{array}{l}\text { Os processos e programas de } \mathrm{RH} \\
\text { aumentem a capacidade de mudança da } \\
\text { organização (4) }\end{array}$ & 0 & 0 & 0 & 0 & 0 \\
\hline
\end{tabular}

Q9 A eficácia da área de $\mathrm{RH}$ é medida por sua capacidade de...

\begin{tabular}{|c|c|c|c|c|c|}
\hline $\begin{array}{c}\text { Ajudar a fazer com que a estratégia } \\
\text { aconteça (1) } \\
\text { Liberar com eficiência os processo }\end{array}$ & 0 & 0 & 0 & 0 & 0 \\
de $\mathrm{RH}(2)$ \\
$\begin{array}{c}\text { Ajudar os funcionários a satisfazer } \\
\text { necessidades pessoais (3) } \\
\begin{array}{c}\text { Ajudar uma organização a antecipar- } \\
\text { se e adaptar-se a questões futuras (4) }\end{array}\end{array}$ & 0 & 0 & 0 & 0 & 0 \\
\hline
\end{tabular}


Q10 O RH é visto como...

\begin{tabular}{|l|l|l|l|l|l|}
\hline & $1(1)$ & $2(2)$ & $3(3)$ & $4(4)$ & $5(5)$ \\
\hline Parceiro estratégico (1) & 0 & 0 & 0 & 0 & 0 \\
Especialista administrativo (2) & 0 & 0 & 0 & 0 & 0 \\
Defensor de funcionários (3) & 0 & 0 & 0 & 0 & 0 \\
Agente da mudança (4) & 0 & 0 & 0 & 0 & 0 \\
\hline
\end{tabular}

Q11 O RH dedica tempo a...

\begin{tabular}{|l|l|l|l|l|l|}
\hline Questões estratégicas (1) & $1(1)$ & $2(2)$ & $3(3)$ & $4(4)$ & $5(5)$ \\
\hline $\begin{array}{l}\text { Questões operacionais (2) } \\
\text { Ouvir e responder aos funcionários }\end{array}$ & 0 & 0 & 0 & 0 & 0 \\
(3) $\quad$ Apoiar novos comportamentos para & 0 & 0 & 0 & 0 & 0 \\
$\begin{array}{c}\text { Apanter a empresa competitiva (4) } \\
\text { mana }\end{array}$ & 0 & 0 & 0 & 0 & 0 \\
\hline
\end{tabular}

Q12 O RH participa ativamente em...

\begin{tabular}{|c|c|c|c|c|c|}
\hline Planejamento empresarial (1) & $1(1)$ & $2(2)$ & $3(3)$ & $4(4)$ & $5(5)$ \\
\hline $\begin{array}{c}\text { Conceber e facilitar a execução dos } \\
\text { processos do setor de RH (2) } \\
\text { Ouvir e responder aos funcionários }\end{array}$ & 0 & 0 & 0 & 0 & 0 \\
(3) $\begin{array}{l}\text { Renovação, mudança } \\
\text { Reu ou } \\
\text { transformação da organização (4) }\end{array}$ & 0 & 0 & 0 & 0 & 0 \\
\hline
\end{tabular}

Q13 O RH trabalha para...

\begin{tabular}{|c|c|c|c|c|c|}
\hline $\begin{array}{c}\text { Ajustar as estratégias de RH à } \\
\text { estratégia empresarial (1) } \\
\begin{array}{c}\text { Monitorar processos } \\
\text { administrativos (2) }\end{array}\end{array}$ & 0 & 0 & 0 & 0 & 0 \\
$\begin{array}{c}\text { Oferecer assistência para ajudar os } \\
\text { funcionários a satisfazer necessidades } \\
\text { familiares e pessoais (3) } \\
\begin{array}{c}\text { Remodelar comportamento para a } \\
\text { mudança organizacional (4) }\end{array}\end{array}$ & 0 & 0 & 0 & 0 & 0 \\
\hline
\end{tabular}


Q14 O RH desenvolve processos e programas para...

\begin{tabular}{|c|c|c|c|c|c|}
\hline & $1(1)$ & $2(2)$ & $3(3)$ & $4(4)$ & $5(5)$ \\
\hline $\begin{array}{l}\text { Encadear estratégias de } \mathrm{RH} \text { para } \\
\text { realizar a estratégia empresarial (1) }\end{array}$ & 0 & 0 & 0 & 0 & 0 \\
\hline $\begin{array}{cc}\text { Processar } & \text { eficientemente } \\
\text { documentos e transações (2) }\end{array}$ & 0 & 0 & 0 & 0 & 0 \\
\hline $\begin{array}{l}\text { Cuidar das necessidades pessoais } \\
\text { dos funcionários (3) }\end{array}$ & 0 & 0 & 0 & 0 & 0 \\
\hline $\begin{array}{c}\text { Ajudar a organização a se } \\
\text { transformar (4) }\end{array}$ & 0 & 0 & 0 & 0 & 0 \\
\hline
\end{tabular}

Q15 A credibilidade da área de $\mathrm{RH}$ provém de...

\begin{tabular}{|c|c|c|c|c|c|}
\hline $\begin{array}{c}\text { Ajudar a cumprir metas } \\
\text { estratégicas (1) }\end{array}$ & $1(1)$ & $2(2)$ & $3(3)$ & $4(4)$ & $5(5)$ \\
Aumentar a produtividade (2) & 0 & 0 & 0 & 0 & 0 \\
$\begin{array}{c}\text { Ajudar os funcionários a atender } \\
\text { suas necessidades pessoais (3) }\end{array}$ & 0 & 0 & 0 & 0 & 0 \\
$\begin{array}{c}\text { Fazer com que a mudança } \\
\text { aconteça (4) }\end{array}$ & 0 & 0 & 0 & 0 & 0 \\
\hline
\end{tabular}

Q20 Você tem alguma sugestão ou crítica para a área de recursos humanos?

\section{$1^{\circ}$ Entrevista presencial}

Nessa primeira parte serão apenas informações descritivas para poder auxiliar na análise do trabalho

Você trabalha em $\mathrm{RH}$ ?

Sim, trabalho atualmente

Não, mas já trabalhei

Não, nunca trabalhei

\section{Gênero}

Masculino

Feminino

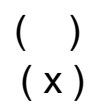


Idade

18 a 23 anos

24 a 29

30 a 34

35 a 39

40 anos ou mais

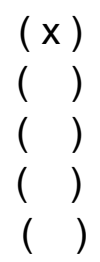

Cargo que ocupa

Estagiário

( $\mathrm{x}$ )

Analista

Consultor

Gerente

Diretor

Outros

Tempo na área

6 meses

1 ano

1 ano e meio

2 anos

Mais de 2 anos

Qual área do $\mathrm{RH}$ você atua ou atuou?

Recrutamento e seleção

Treinamento

Departamento pessoal

Segurança do trabalho

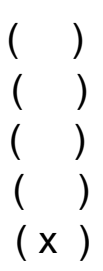

Outros

A pesquisa a seguir explora diferentes papéis que a função de $\mathrm{RH}$ pode desempenhar dentro de sua empresa. Pontue por favor, a qualidade corrente de cada uma das seguintes atividades de recursos humanos, utilizando uma escala de cinco pontos (1 para baixa; 5 para alta)

Qualidade

corrente

(1 a 5)

1. O RH ajuda a empresa a...

1. Alcançar as metas empresariais

2. melhorar a eficiencia operacional

3. cuidar das necessidades pessoais dos funcionários

4. adaptar-se a mudança

2. O rh participa na Accenture...

1. Processo de definição de estratégia 
2. desenvolvimento dos projetos de rh

3. aumento da dedicação dos funcionários

4. modelagem de mudança de cultura para renovação e transformação ( 5 )

3. O RH garante que...

1. as estratégias de RH estejam ajustadas a estratégia empresarial ( 5 )

2. os processos de RH sejam administrados com eficiência (5 )

3. as politicas e os programas de $\mathrm{RH}$ respondam às necessidades pessoais dos funcionários

4. os processos e os programas de $\mathrm{RH}$ aumentem a capacidade de mudança da organização

4. A eficácia da área de recursos humanos na accenture é medida por sua capacidade de...

1. ajudar a fazer com que a estratégia aconteça

2. liberar com eficiencia os processos de $\mathrm{RH}$

3. ajudar os funionários a satisfazer necessidades especiais

4. ajudar a organização a antecipar-se e adaptar-se a questões futuras

5. O RH é visto como...

1. Parceiro estratégico

2. especialista admistrativo

3. Defensor dos funcionários

4. Agente da mudança

6. O RH dedica o tempo a....

1. Questões estratégicas

2. Questões operacionais

3. Ouvir e responder os funcionários

4. apoiar novos comportamentos para manter a empresa competitiva

7. O RH participa ativamente em...

1. planejamento empresarial

2. Facilitar a execução das atividades de RH da empresa

3. Ouvir e responder os funcionários

4. renovação, mudança ou transformação da organização

8. O RH trabalha para...

1. Ajustar a estratégia de RH para a estratégia empresarial

2. monitorar processos administrativos

3. oferecer assistência para ajudar os funcionários a satisfazer necessidades famíliares e pessoais

4. remodelar o comportamento para a mudança organizacional

9. O RH desenvolve processos e programas para...

1. encadear estratégia de $\mathrm{RH}$ para realizar a estratégia empresarial ( 5 )

2. processar eficientemente documentos e transações

3. cuidar das necessidades pessoais dos funcionários

4. ajudar a organização a se transformar

10. A credibilidade da área de $\mathrm{RH}$ provém de...

1. ajudar a cumprir as metas estratégicas

2. aumentar a produtividade

3. ajudar os funcionários a atender suas necessidades pessoais

4. fazer com que a mudança aconteça

11. Você tem alguma sugestão ou critica para a área de recursos humanos? 
Eu acho que mais na questão de escutar os funcionários mesmo, no sentido de ver como eles estão sentindo em questão de melhoria que poderia existir, o que que eles acham da empresa.

Obrigado pela participação!

$2^{\circ}$ entrevista individual:

Você trabalha em $\mathrm{RH}$ ?

Sim, trabalho atualmente

Não, mas já trabalhei

Não, nunca trabalhei

Gênero

Masculino

Feminino

Idade

18 a 23 anos

24 a 29

30 a 34

35 a 39

40 anos ou mais

Cargo que ocupa

Estagiário

Analista

Consultor

Gerente

Diretor

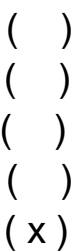

Outros

\section{Tempo na área}

6 meses
1 ano
1 ano e meio
2 anos
Mais de 2 anos


Qual área do $\mathrm{RH}$ você atua ou atuou?

Recrutamento e seleção

Treinamento

Departamento pessoal

Segurança do trabalho

Outros: Gestão de pessoas

A pesquisa a seguir explora diferentes papéis que a função de $\mathrm{RH}$ pode desempenhar dentro de sua empresa. Pontue por favor, a qualidade corrente de cada uma das seguintes atividades de recursos humanos, utilizando uma escala de cinco pontos (1 para baixa; 5 para alta)

12. O RH ajuda a empresa a...

1. Alcançar as metas empresariais

2. melhorar a eficiencia operacional

3. cuidar das necessidades pessoais dos funcionários

4. adaptar-se a mudança

13. O RJ participa na Accenture...

1. Processo de definição de estratégia

2. desenvolvimento dos projetos de $\mathrm{RH}$

3. aumento da dedicação dos funcionários

4. modelagem de mudança de cultura para renovação e transformação ( 4 )

14. O RH garante que...

1. as estratégias de $\mathrm{RH}$ estejam ajustadas a estratégia empresarial

2. os processos de RH sejam administrados com eficiência

3. as politicas e os programas de $\mathrm{RH}$ respondam às necessidades pessoais dos funcionários

4. os processos e os programas de $\mathrm{RH}$ aumentem a capacidade de mudança da organização

15. A eficácia da área de recursos humanos na accenture é medida por sua capacidade de...

1. ajudar a fazer com que a estratégia aconteça

2. liberar com eficiencia os processos de $\mathrm{RH}$

3. ajudar os funionários a satisfazer necessidades especiais

4. ajudar a organização a antecipar-se e adaptar-se a questões futuras

16. O RH é visto como...

1. Parceiro estratégico

2. especialista admistrativo

3. Defensor dos funcionários

4. Agente da mudança

17. O RH dedica o tempo a....

1. Questões estratégicas

2. Questões operacionais

3. Ouvir e responder os funcionários

4. apoiar novos comportamentos para manter a empresa competitiva 
18. O RH participa ativamente em...

1. planejamento empresarial (3)

2. Facilitar a execução das atividades de RH da empresa

3. Ouvir e responder os funcionários

4. renovação, mudança ou transformação da organização

19. O RH trabalha para...

1. Ajustar a estratégia de RH para a estratégia empresarial

2. monitorar processos administrativos

3. oferecer assistência para ajudar os funcionários a satisfazer necessidades famíliares e pessoais

4. remodelar o comportamento para a mudança organizacional

20. O RH desenvolve processos e programas para...

1. encadear estratégia de $\mathrm{RH}$ para realizar a estratégia empresarial

2. processar eficientemente documentos e transações

3. cuidar das necessidades pessoais dos funcionários

4. ajudar a organização a se transformar

21. A credibilidade da área de RH provém de...

1. ajudar a cumprir as metas estratégicas

2. aumentar a produtividade

3. ajudar os funcionários a atender suas necessidades pessoais

4. fazer com que a mudança aconteça

22. Você tem alguma sugestão ou critica para a área de recursos humanos?

A sugestão é tentar sempre se colocar no lugar do outro, perceber as coisas que estão acontecendo na empresa, tentar agir estratégicamente, é mais por ai do que já está acontecendo mesmo.

$3^{\circ}$ entrevista individual:

Você trabalha em $\mathrm{RH}$ ?

Sim, trabalho atualmente

Não, mas já trabalhei

Não, nunca trabalhei

\section{Gênero}

Masculino

Feminino

Idade

18 a 23 anos

24 a 29

30 a 34

35 a 39

40 anos ou mais 


\section{Cargo que ocupa}

$\begin{array}{ll}\text { Estagiário } & (\mathrm{x}) \\ \text { Analista } & (\mathrm{)}) \\ \text { Consultor } & (\text { ) } \\ \text { Gerente } & (\text { ) } \\ \text { Diretor } & (1)\end{array}$

Outros

\section{Tempo na área}

6 meses

1 ano

1 ano e meio

2 anos

Mais de 2 anos

Qual área do $\mathrm{RH}$ você atua ou atuou?

\begin{tabular}{|c|c|}
\hline Recrutamento e seleção & $(x)$ \\
\hline Treinamento & ( ) \\
\hline Departamento pessoal & \\
\hline Segurança do trabalho & ( \\
\hline
\end{tabular}

Outros:

A pesquisa a seguir explora diferentes papéis que a função de $\mathrm{RH}$ pode desempenhar dentro de sua empresa. Pontue por favor, a qualidade corrente de cada uma das seguintes atividades de recursos humanos, utilizando uma escala de cinco pontos (1 para baixa; 5 para alta)

23. O RH ajuda a empresa a...

1. Alcançar as metas empresariais

2. melhorar a eficiencia operacional

3. cuidar das necessidades pessoais dos funcionários

4. adaptar-se a mudança

24. O RH participa na Accenture...

1. Processo de definição de estratégia

2. desenvolvimento dos projetos de $\mathrm{RH}$

3. aumento da dedicação dos funcionários

4. modelagem de mudança de cultura para renovação e transformação ( 5 )

25. O RH garante que...

1. as estratégias de RH estejam ajustadas a estratégia empresarial

2. os processos de RH sejam administrados com eficiência

3. as politicas e os programas de $\mathrm{RH}$ respondam às necessidades pessoais dos funcionários

4. os processos e os programas de $\mathrm{RH}$ aumentem a capacidade de mudança da organização 
26. A eficácia da área de recursos humanos na accenture é medida por sua capacidade de...

1. ajudar a fazer com que a estratégia aconteça

2. liberar com eficiencia os processos de RH

3. ajudar os funionários a satisfazer necessidades especiais

4. ajudar a organização a antecipar-se e adaptar-se a questões futuras

27. O RH é visto como...
1. Parceiro estratégico
2. especialista admistrativo
3. Defensor dos funcionários
4. Agente da mudança

28. O RH dedica o tempo a....

1. Questões estratégicas

2. Questões operacionais

3. Ouvir e responder os funcionários

4. apoiar novos comportamentos para manter a empresa competitiva

29. O RH participa ativamente em...

1. planejamento empresarial

2. Facilitar a execução das atividades de RH da empresa

3. Ouvir e responder os funcionários

4. renovação, mudança ou transformação da organização

30. O RH trabalha para...

1. Ajustar a estratégia de RH para a estratégia empresarial

2. monitorar processos administrativos

3. oferecer assistência para ajudar os funcionários a satisfazer necessidades famíliares e pessoais

4. remodelar o comportamento para a mudança organizacional

31. O RH desenvolve processos e programas para...

1. encadear estratégia de $\mathrm{RH}$ para realizar a estratégia empresarial (4)

2. processar eficientemente documentos e transações

3. cuidar das necessidades pessoais dos funcionários

4. ajudar a organização a se transformar

32. A credibilidade da área de RH provém de...

1. ajudar a cumprir as metas estratégicas

2. aumentar a produtividade

3. ajudar os funcionários a atender suas necessidades pessoais

4. fazer com que a mudança aconteça

33. Você tem alguma sugestão ou critica para a área de recursos humanos?

Não 